\title{
Why Do We Make Sport: The Importance of Psycho-Social Motivations in Adult Sports Participation
}

\author{
Jansanem Jular ${ }^{1} \&$ Berna Tari Kasnakoglu ${ }^{1}$ \\ ${ }^{1}$ Department of Business Administration, TOBB University of Economics and Technology, Ankara, Turkey \\ Correspondence: Jansanem Jular, Department of Business Administration, TOBB University of Economics and \\ Technology, Ankara, Turkey. E-mail: jansanemjular@gmail.com
}

Received: March 14, 2017 Accepted: April 12, $2017 \quad$ Online Published: May 29, 2017

doi:10.5539/ijms.v9n3p39 URL: http://doi.org/10.5539/ijms.v9n3p39

\begin{abstract}
This study is swayed by the idea of how people might be motivated to engage in different types of sports, and how enduring these motivations might be. The importance of the research question stems from an observable trend among people who are willing to experience different sports for the sake of fun and pleasure, as well as an academic need to develop a better understanding of the physical, psychological, and social factors that shape people' sports choices. With this purpose, this study summarizes the results of a questionnaire asking 242 respondents the extent to which they are motivated by each single motive listed. General descriptive results do not explain much of sport behavior; however multinomial regression, exploring a causal link between motivation types and sports types reveals more informative conclusions. Results emphasize the importance of a psycho-social account of sports participation since health is found to be an insignificant motivator.
\end{abstract}

Keywords: sports person behavior, sports motivations, sports consumption, sports commitment

\section{Introduction}

In the context of sports, there are people who are completely indifferent to sports and those that are highly involved. Excluding professional sports players, many lay people today are somewhat interested in different types of sports. Some climb, some run, and some dance. Some do this occasionally, some on a regular basis. So what drives people to engage in doing sports? Is this impetus permanent? Is it possible for people to stop doing sports or switch to another sport type when their desires are satisfied?

Intrigued by these and other questions, this research aims to explore and understand if people are motivated in different ways when choosing particular types of sports, and whether they are committed to this sport for a long period of time. Relying on self determination theory (Deci \& Ryan, 2002), this study assumes that sports choices are determined and shaped by motivations based on either intrinsic motives or extrinsic influences (Riley \& Smith, 2011; Ommundsen, Lemyre, Abrahamsen, \& Roberts, 2010). Just as people might consume other experiential products and services to fulfill a variety of different needs and desires, they might engage in one sports activity based on one or more psychological and social motivations, as well as more "objective", physical reasons.

Previous studies have already confirmed the importance of psychological and social factors in affecting exercise and sport motivations (Halldorsson, Helgason, \& Thorlindsson, 2012; Battistelli, Montani, Bertinato, Uras, \& Guicciardi, 2012; Gill, Gross, \& Huddleston, 1983). Therefore, looking at sports activities strictly from a physical engagement perspective, even for professional sport players, may result in an insufficient, if not erroneous, conclusion. Moreover, doing sports might be included as a leisure interest and as another experiential consumption activity, rather than mere physical activity. This study is an attempt to investigate whether and how psychological and social motivations might be as important as physical motivations regarding adult sports participation.

\section{Literature: Motivations for Sports Participation}

Extant literature contains various studies investigating motivations of sports enthusiasms. A very large portion of this literature has been involved with spectator motivations (e.g., Hall \& O’Mahony, 2006; Funk, Filo, Beaton, \& Pritchard, 2009; Trail \& James, 2001; Grove, Dorsch, \& Hopkins, 2012) and fan motivations (e.g., Wann, Schrader, \& Wilson, 1999; Wann, Grieve, Zapalac, \& Pease, 2008). Some studies have particularly explored the 
relationship between motives and sports attendance, and come up with variables that moderate this relationship such as involvement with a sports team (Kim, Trail, \& Magnusen, 2013). Realizing that physical exercise cannot be the sole determinant of sports choice, the experiential and "fun" component have been explicitly mentioned in several studies in different literatures (e.g., Holbrook, Chestnut, Oliva, \& Greenleaf, 1984), in conjunction with accounts emphasizing sports attendance as a leisure time activity. For this reason, the entertainment and excitement aspect of sport spectatorship has received considerable attention (e.g., Kahle \& Riley, 2004). As part of this entertainment function, people can also find themselves in a sports activity just because they want to be with family and friends (Robertson \& Pope, 1999), thus socialization has been discussed as another important motivator.

Fewer studies have focused on the motivations of people who actually "consume" the activity by physically engaging in at least one type of sports. Some researchers have investigated the effects of general market conditions on professional sports people' behavior (e.g., Byon, Zhang, \& Connaughton, 2010) or the behavioral tendency to attend sport and health clubs (e.g., Ho, Yen, Su, Hsueh, \& Huang, 2012), while many researchers have focused on one specific sports category, such as adventure sports (Kerr \& Mackenzie, 2012), action sports (Ko, Park, \& Claussen, 2008), fencing and athletics (Gillet, Berjot, Vallerand, Amoura, \& Rosnet, 2012), soccer (Tokuyana \& Greenwell, 2011), running (Rohm, Milne, \& McDonald, 2006), and skating (Green-Demers, Pelletier, Stewart, \& Gushue, 1998), and swimming (Gould, Feltz, \& Weiss, 1985). Obviously, the level of motivations is an important factor for people who engage in sports (Caro \& García, 2008; Gillet et al., 2012), but the type of motivations is also important.

Both psychological and sociological accounts have been made in an attempt to understand people' motivations toward active participation. For instance, Prichard \& Tiggeman (2011) have investigated the effects of body image on sports participation, while Wheeler (2011) has explored the effects of family culture, illustrating both psychological and social issues. These motives can be discussed under the titles of intrinsic and extrinsic motives (Bollók, Takács, Kalmár, \& Dobay, 2011; Deci \& Ryan, 2002).

In order to arrive at a complete understanding of active sports participation motivations and to possibly generalize the results, it is necessary to include an assortment of different sports categories. As such, one can engage in yoga activities, play tennis, or climb a mountain for different sets of motivations. Studies which involve more than one type of sports include the sports motivation scale (SMS), translated into English by Pelletier et al. (1995), which measures whether the sports-person is intrinsically motivated, extrinsically motivated, or amotivated. Martens \& Webber (2002) have worked on developing this scale; while Mallett et al. (2007) have come up with a different version of this scale, the SMS-6. Pelletier et al. (2013) have recently published a revised version of the original SMS, which they have called the SMS-II.

Another integrative attempt has been made to explore motivations of spectators and participants in a comparative fashion (McDonald, Milne, \& Hong, 2002). Based on Maslow's hierarchy of needs, their motivation scale has included a variety of constructs and a variety of different types of sports. In addition, Gill et al. (1983) have developed and several researchers (e.g., Salguero, González-Boto, Tuero, \& Márquez, 2003; Gould et al., 1985; Sit \& Lindner, 2006; Barber, Sukhi, \& White, 1999) have used the Participation Motivation Scale, and focused on the motivations of young people and children. They have identified that such psychological and social motives as fun or challenge can be predictors of sports participation.

\section{Research Questions}

Building on the idea that motivations might differ across different sport types, attempts by researchers, who were briefly discussed above, are very appreciable. They have included different sport contexts and reached convincing conclusions pertaining to sports behavior. An important area which remains unnoticed is why adult people engage in which sports. In other words, a clear linkage between motivation types and sports types is missing. There are post-hoc and mainly descriptive explanations for how people with different sport interests are motivated, but we still do not know whether those motivations affect the decision to choose that specific sport or not. Further knowledge regarding this largely neglected casual link would enrich our understanding of sports participation behavior, and provide helpful information for sports club and brand executives, as well as public policy managers.

Therefore, it is the intention of this study to address the above-mentioned limitations in sport motivation research, and

1) categorize sports types and motivation types,

2) investigate the causal relationship between these categories, and 
3) explore further analyses as regards to the concept of commitment and the effects of a few demographic variables.

This study, therefore, aims to explain why adult people engage in particular sports. To arrive at such conclusions, it is necessary to categorize sports, as well as motivations, in a theoretically meaningful way. Previous studies either have not categorized sports at all, leaving only scattered discussions about motivation-sports relationships, or categorized sports but did not connect the overall discussion to these groups. This study groups sport types based on the presence and/or involvement of other people. By expressing sports into categories of individual, one-to-one, and team sports, it will be possible to understand whether different motivations are connected to selfor other-related issues. Motivation categories are constructed based on empirical data, and these categories will be explained in subsequent sections, as part of the factor analysis.

In order to arrive at a robust explanation for the motivation-sports relationship, it is also necessary to look at the level of commitment. Involvement can be conceptualized as the level of activeness in the specific sports category, ranging from full involvement as a player to a more passive role such as spectatorship (Constantinescu, 2013); but in this study, commitment is operationalized as the duration spent doing the same sports type. Previous studies investigating this dimension of actual sports participation have inferred that demographic factors cannot be generalized in assessing the level of commitment (e.g., Casper \& Stellino, 2008). In fact, "enjoyment" (Casper \& Stellino, 2008) was found to be the strongest predictor of commitment, which may remain too broad as a motivation category.

\section{Methodology}

\subsection{Sample and Measures}

The sample consists of 242 individuals, who are living in Ankara, capital city of Turkey, and have been engaged in at least one type of sports at the time of the survey or in the past. The questionnaire is self-administered without any credits or presents in return. Average age is 25.64 ranging from 15 to 62 . Average number of years the participants have been doing sports is 6.75 years ranging from six months to 25 years. $30 \%$ of the sample is composed of females, while $51 \%$ of the sample is a graduate of least the primary school, and $49 \%$ of college or higher. Mean personal monthly disposable income is 1628 Turkish Liras (765 US Dollars), going as high as 15,000 Turkish Liras (7.050 US Dollars) per month.

A total of 46 different motivations are listed in the questionnaire, and all questions are derived from the related literature, especially including Pelletier et al. (1995) and Gill et al. (1983). The alpha value for these items is found to be .944, indicating a highly reliable scale. The questions are asked in the form of 5-point Likert items, asking respondents how much they agree with the written statement as a motivating factor. The questionnaire has a second part, where respondents are asked about their demographic characteristics, as well as the type of sports they are engaged with.

\section{Results}

Motivations are reduced to eight categories by conducting a factor analysis with varimax rotation. Factor loadings are presented in Appendix A. A closer examination of the factor loadings have revealed that items congregate on a meaningful basis. Factors are named to reflect these meanings, namely, pleasure, good looks, social capital, health, self confidence, high spirits, morale, teamwork, affair, and sleep. These factors are somewhat in line with previous motivation categories. For instance, Gill et al. (1983) have found that young people are motivated by status, fitness, team atmosphere, skill development, energy release, friendship and fun. The factors identified in this study also seem to reflect physical (good looks, sleep, and health), psychological (pleasure, self confidence, high spirits, and morale), and social (teamwork, social capital, and affair) drives. The factors and associated mean scores (calculated by taking an average of all items that were loaded on that factor) are presented in Table 1 . Table 1 also illustrates the mean values which are significantly different from the overall mean of 3.55 . 
Table 1. Mean scores

\begin{tabular}{lll}
\hline Factor Name & Mean & Factor Meaning \\
\hline Pleasure & $3.92^{* *}$ & General positive feeling, giving pleasure like a hobby \\
Good Looks & 3.57 & Physical bodily attractiveness, fit body \\
Social Capital & $3.80^{* *}$ & Sports in place of connectedness and social benefits \\
Health & $4.08^{* *}$ & Physical health, good body condition \\
Self Confidence & $3.75^{* *}$ & Respect for self and moral advancement \\
High Spirits & 3.53 & Joy and elevated positive feelings \\
Morale & 3.58 & Forgetting bad things in life, focus on something better \\
Teamwork & $3.42^{*}$ & Team spirit and connection \\
Affair & $2.27^{* *}$ & Possibility for finding a partner \\
Sleep & 3.60 & Good sleep \\
OVERALL & 3.55 & \\
\hline
\end{tabular}

Note. $*$ significant at $90 \%, * *$ significant at $95 \%$, based on one-sample t-test, test value $=3.55, \mathrm{df}=241$.

Table 1 shows that pleasure, social capital, health, and self confidence are significantly more powerful motivators, while, on average, teamwork and affair are significantly less powerful motivators. However, the composite factor means do not create a meaningful explanation for behavioral differences because several means are quite high, and also because they do not differentiate among sports types. Therefore, without further analyses, descriptive findings would not add to our knowledge on the effects of motivations.

In order to see which specific sports types have been chosen under each motivation type, Table 2 is generated. A participant's dominant motivation type has been determined by looking at the mean values for each motivation type. The one with the highest mean has been selected as the dominant motivation for that specific individual. If the person can be attributed to more than one dominant motivation type, then the individual is taken out of the analysis, leaving 171 individuals at the end. Table 2 also excludes people with two different sports as their individual motivations might be different, leaving 142 individuals. Therefore, some data is lost in Table 2 in order to attain a more dependable comparison.

Table 2. Individual types of sports vs. dominant motivation type

\begin{tabular}{|c|c|c|c|c|c|c|c|c|c|c|c|}
\hline \multirow[t]{2}{*}{ Type of Sports } & \multicolumn{11}{|c|}{ Motivation $^{\mathrm{a}}$} \\
\hline & 1 & 2 & 3 & 4 & 5 & 6 & 7 & 8 & 9 & 10 & TOTAL \\
\hline Fitness & & 2 & 1 & 13 & 2 & 1 & & 1 & & 2 & 22 \\
\hline Handball & 3 & & & 2 & 2 & 1 & & 7 & 1 & 4 & 20 \\
\hline Football & 2 & & 5 & 4 & 1 & & & 4 & 2 & 2 & 20 \\
\hline Basketball & 1 & 1 & 3 & 5 & & & & 2 & 1 & 3 & 16 \\
\hline Swimming & 3 & 1 & 1 & 4 & & & & & & 4 & 13 \\
\hline Volleyball & 2 & & 1 & 1 & & & & 4 & & & 8 \\
\hline Table tennis & 2 & & 3 & 1 & & & 1 & & & & 7 \\
\hline Tennis & 1 & & 3 & 2 & & & & & & & 6 \\
\hline Walking & & & & 5 & & 1 & & & & & 6 \\
\hline Running & & & 2 & 1 & & & & & & 1 & 4 \\
\hline Athletics & 1 & 1 & & & & & & & 1 & & 3 \\
\hline Body building & & 1 & & & & & & & 1 & & 2 \\
\hline Skiing & 1 & & 1 & & & & & & & & 2 \\
\hline Meditation & & & & 1 & & & & & & 1 & 2 \\
\hline Horse riding & & & & 1 & & & & & & & 1 \\
\hline Bicycling & & & & & & & & & & 1 & 1 \\
\hline Mountain & & & & & & & & & & 1 & 1 \\
\hline Fencing & 1 & & & & & & & & & & 1 \\
\hline Folk dances & & & & 1 & & & & & & & 1 \\
\hline Boxing & & & & 1 & & & & & & & 1 \\
\hline Archery & & 1 & & & & & & & & & 1 \\
\hline Wind surfing & & & & & & & & & 1 & & 1 \\
\hline Squash & & & & & & & 1 & & & & 1 \\
\hline Martial arts & & & & 1 & & & & & & & 1 \\
\hline Sailing & & & & & & & & & & 1 & 1 \\
\hline TOTAL & 17 & 7 & 20 & 43 & 5 & 3 & 2 & 18 & 7 & 20 & 142 \\
\hline
\end{tabular}

Note. (a) 1-Pleasure, 2-Good Looks, 3-Social Capital, 4-Health, 5-Self Confidence, 6-High Spirits, 7-Morale, 8-Teamwork, 9-Affair, 10-Sleep. 
It is observed that health is a key motivator and morale is a trifling motivator. The motivation of pleasure is especially valid for handball and swimming, while social capital is prevalent among people of football, basketball, table tennis, and tennis. Teamwork is motivator for people of handball, football, and volleyball, while sleep seems to be important for people playing handball and volleyball.

\subsection{Sports versus Motivations}

General results summarized above are quite scattered without further analysis, justifying a need to classify sports. Based on the discussion made earlier, sports types were categorized under the groups of individual sports, one-to-one sports, and team sports. If the respondent wrote more than one types of sports, then that person's reply to the question was not taken into consideration. 13 individuals' replies were taken out of the analysis for this reason.

Multinomial logistic regression is conducted (Table 3), where the dependent variable was the type of sports in three categories and the independent variables are ten motivation factor scores, identified in the initial analysis, which are the covariates. Factor scores using the regression method were utilized (DiStefano, Zhu, \& Mîndrilă, 2009). Income and gender are assumed to affect the type of sports chosen, and so they are also taken as independent variables. In Table 3, female gender is coded as zero. Model is significant at $.000\left(\chi^{2}=127.064\right.$, $\mathrm{df}=24$ ), and Pseudo R-square statistics are found as .451, .525, and .306 for Cox and Snell, Nagelkerke, and McFadden respectively.

Table 3. Parameter estimates, multinomial logistic regression

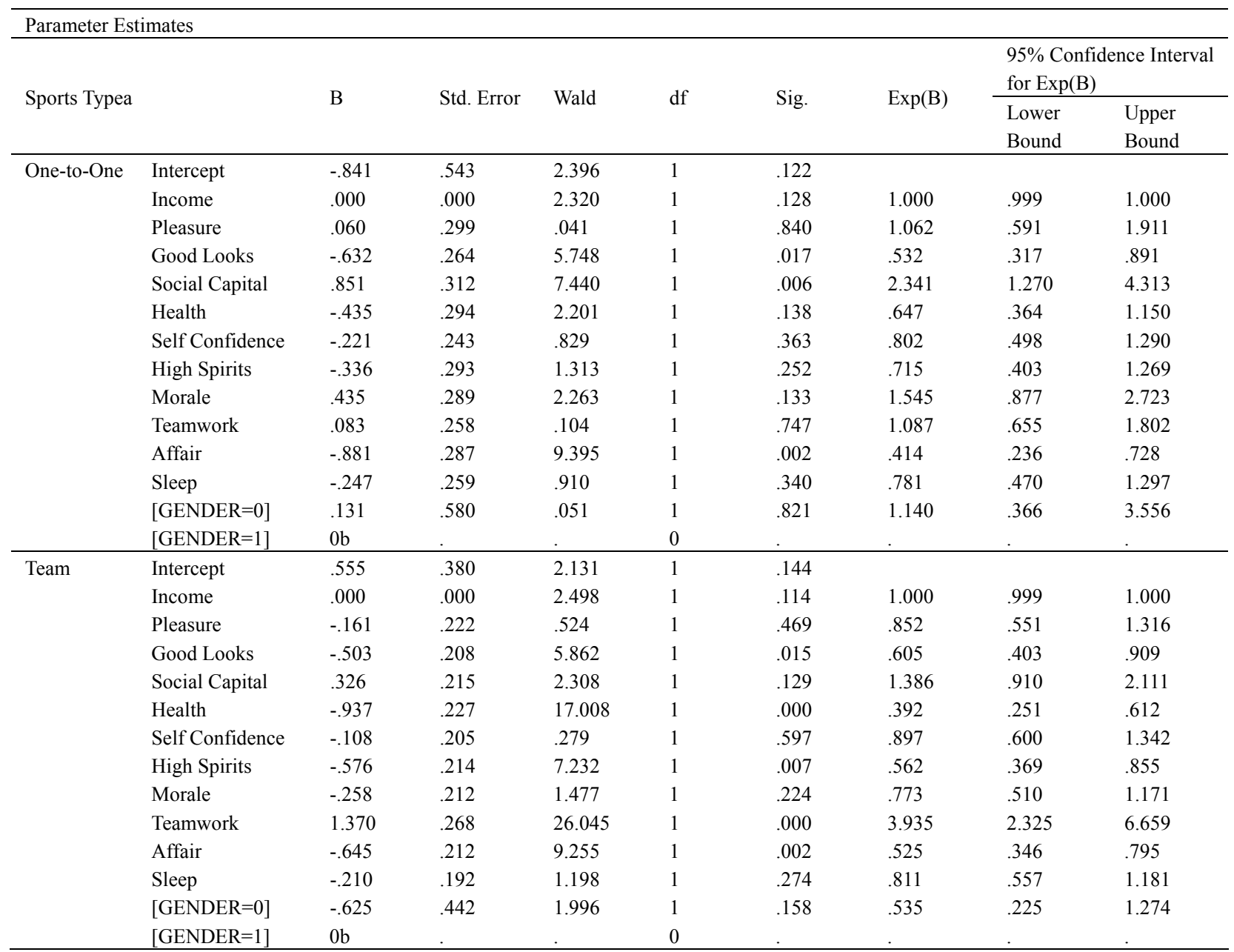

Note. a. The reference category is: 1.00 . b. This parameter is set to zero because it is redundant.

Looking at the relationship between motivation types and sports types, it is obvious that psychological and social needs dominate physical needs. In other words, physical motivations do not create enough difference for 
choosing a particular type of sport. Results also indicate that gender or income is not influential in sport type decisions. This has important implications because people cannot be differentiated based on mere demographic factors.

Quite significant results were obtained for other motivation categories. Participants choose individual sports over one-to-one sports when they are motivated by the ideal of an attractive body. When they seek a romantic relationship, they also choose individual sports rather than one-to-one sports. These two motivations are meaningfully connected to each other, too, indicating that people may choose individual sports so that they can physically make themselves more attractive, and possibly find a partner. One-to-one (and possibly team sports) would not be appropriate for this motivation because the person needs to attend him/herself and/or the environment, rather than other people in the same activity. On the contrary, if the person is motivated by achieving social capital, such as improving social skills or developing an aptitude for expressing him/herself, then the individual is inclined to engage in one-to-one sports rather than individual sports. This indicates that people may choose another companion to enrich his/her social capital.

Looking at the results related to team sports, people are almost four times more likely to engage in team sports (compared to individual sports) when they are motivated by teamwork, which includes such questionnaire items as feeling connected to other people. However, people are more likely to choose individual sports (rather than team sports) when they are motivated by achieving good looks and having an affair, similar to the finding above. In addition, people choose individual sports for health reasons, too, which is understandable as each person requires a different, individual type of training due to different health conditions including age, weight, and metabolism. Lastly, team sports are not found appropriate if the individual wants to feel good about her/himself, as the person probably needs to be with herself/himself alone.

No single sports type was found to be significantly more satisfactory when the person is motivated by pleasure, self confidence, or morale. Pleasure is in fact a general motivation category which puts sports in place of a hobby and as something which provides meaning and which organizes the person's life. According to factor analysis results, pleasure accounts for $9.2 \%$ of total variation based on rotation sums of squared loadings (representing the highest change in variance), however this component is not able to differentiate among people in terms of their sports choice. It seems like any type of sports can fulfill this broad function of pleasure. Similarly, the motivation for self confidence which involves self respect and moral development, can also be satisfied by engaging in any types of sports. Morale represents another generic motivation category, as one can feel connected and more positive by doing different sports. In other words, these three motivations related to one's psychological boost and confidence are not determining factors in choosing particular sport types.

\subsection{Commitment to the Same Sport Type}

Another issue that becomes important in a discussion of motivation and sports types is how persistent this motivation is for the particular individual. Since the questionnaire asked respondents to reply based on one chosen sport type, it was possible to attribute their replies to a particular sport. Commitment is operationalized by the number of years engaged in one sports activity divided by age, and then multiplied by 100 , hence arriving at a percentage of life spent on doing sports. The average level of commitment is found as 26.77. Comparing this average across each motivation category, Table 4 is obtained.

Table 4. Commitment level by motivation type (one sample t-test)

\begin{tabular}{|c|c|c|c|c|c|c|c|c|c|c|c|}
\hline & \multicolumn{10}{|c|}{ Motivation Type $\mathrm{a}^{\mathrm{a}}$} & \multirow[t]{2}{*}{ Average } \\
\hline & 1 & 2 & 3 & 4 & 5 & 6 & 7 & 8 & 9 & 10 & \\
\hline $\begin{array}{l}\text { Commitment } \\
\text { Level } \\
\text { (in percentages) }\end{array}$ & $34.06^{*}$ & 19.17 & 27.84 & $20.91 * *$ & 25.17 & 33.90 & 23.75 & $32.36^{* *}$ & 36.18 & 25.41 & 26.77 \\
\hline
\end{tabular}

Table 4 illustrates that the highest level of commitment is observed among people who are motivated by having an affair and the lowest level of commitment is observed among people who are motivated by good looks, although these results are not significant. People are significantly more committed to doing sports when they are motivated by pleasure and teamwork. Although pleasure does not differentiate among sport types, it does provide enough stimulus for people to continue doing the same sports over the years. Similarly, the enthusiasm which stem from a teamwork rationale is very strong. However, people are significantly less committed to doing 
sports when they are motivated by health. This finding is quite interesting considering the physically inherent nature of doing sports.

\section{Discussion and Conclusion}

This study has revealed that physical needs may never override the importance of psychological and social needs when people choose a specific type of sports. Table 1 and Table 2 show that health is the most common motivator, although this variable has proved to be not powerful enough to differentiate among all sport types (Table 3) and not an enduring motivator (Table 4). To put it differently, psychological and social motivations may represent more influential factors in choosing sports than health. Although the importance of psychological and social motivations has been pointed out in previous studies, here it is also revealed that the physical motivations do not change the speculated relationships, even though the mean value for health is the highest. Health is a significant motivator in favor of individual sports over team sports, however, people are only 0.92 times more likely to choose individual sports.

The model explains that some generic motivation categories, i.e., pleasure, self confidence, and morale, are not specific enough to differentiate among different sport types, either. However, it seems that people choose one-to-one sports over individual sports when they are motivated by social capital, whereas they choose individual sports when they are motivated by good look and affair. They choose individual sports over team sports when they are motivated by good looks, health, high spirits, and affair, whereas they choose team sports when they are motivated by teamwork.

The above conclusion has important practical implications. For instance, a sports club manager may want to single out the effects of different sets of sports with the perspective of psycho-social motivations. It is possible that a treadmill and a dumbbell in the same room may evoke different motivations. A strategic segmentation of sport types would lead to better and longer-term participant satisfaction. Noticeably, health is not a good motivator. People can choose a variety of individual sports (rather than team sports) when they are motivated by health however they would not continue to be motivated. Therefore, it is necessary that professionals understand the primary motivations that actually guide and shape people's sport behavior. In addition, policy makers may want to emphasize the psychological benefits of doing sports, instead of focusing only on health benefits. Apparently, a lot of people engage in a long-term relationship with a chosen sport category based on psychological benefits such as high spirits, insomuch as they may be allowed to imitate professional sport players in future sports theme parks. Similarly, social benefits may be pronounced by calling for family- and group-based sportive activities.

This study also brings about the "consumption" characteristic of doing sports. Sports is such an obvious example of the "play" aspect of consumption (Holbrook \& Hirschman, 1982) as participants directly and physically engage in the activity, and this aspect has been studied in a few studies (e.g., Schouten \& McAlexander, 1995; Tumbat \& Belk, 2011; Arnould \& Price, 1993). These studies pointed out the joy and "extraordinary consumption experience" people attain when they engage in different types of adventurous activities such as sky diving or mountain climbing. Nowadays, people can pay for a trip to the moon or literally "enjoy the ride" by agreeing for a one-way ticket to Mars. These high-level feelings of joy, in other words, create a marketplace where people can choose to engage in a physical activity, by also practically entering into a conventional market transaction.

This blurs the distinction between doing sports and doing other types of physically-challenging and enjoyable consumption activities. So one dares to ask, when a person pays as high as $\$ 100,000$ to climb Everest (Tumbat \& Belk, 2011), when they could pay much less (or pay nothing) for the same level of physical training, how should we decide whether the underlying motivation is actually physical? The fun part of doing sports is found to exist in the data, however further research is required to examine why and how people engage in different sports activities for personal pleasure and fantasy, and how others are also involved in its enjoyment. Future research can also investigate whether simultaneous participation in more than one type of sports might be predicted with different clusters of motivations (Agans \& Geldhof, 2012).

The results of this study should be interpreted relative to certain limitations. The study is conducted in Turkey with turkish respondents and the focus of this study is the psycho-social factors affecting sports motivation. However, cultural factors may also be effective and people with different cultures may have different motivations. For example, the results of this study show us that people are more likely to engage in team sports compared to individual sports, but this may be due to the cultural characteristics of Turkish people. Also missing in this research is the influence of the institution organizing the sports activity (Roy \& Goss, 2007). A recent perspective would likely to bring a dyadic relationship between the person and the institution (such as the team 
or the coach). At this context, people may cease to be perceived as the "recipients" of a sports organization but rather as partners to construct and maintain this "service relationship". Similarly, all institutions in this regard, including trainers, club managers, sports brand managers, and sports health assistants may start to directly become involved in people' activities, even in shaping the levels and types of motivations.

\section{References}

Agans, J. P., \& Geldhof, G. J. (2012). Trajectories of participation in athletics and positive youth development: the influence of sport type. Applied Developmental Science, 16(3), 151-165. http://dx.doi.org/10.1080/10888691.2012.697792

Arnould, E., \& Price, L. (1993). River magic: extraordinary experience and the extended service encounter. Journal of Person Research, 20(1), 24-45. https://doi.org/10.1086/209331

Barber, H., Sukhi, H., \& White, S. A. (1999). The influence of parent-coaches on participant motivation and competitive anxiety in youth sport participants. Journal of Sport Behavior, 22(2), 162-172.

Battistelli, A., Montani, F., Bertinato, L., Uras, S., \& Guicciardi, M. (2012). Modelling competence motives and physical exercise intentions: the role of individual, social, and environmental characteristics. International Journal of Sport Psychology, 43(6), 457-478.

Bollók, S., Takács, J., Kalmár, Z., \& Dobay, B. (2011). External and internal sport motivations of young adults. Biomedical Human Kinetics, 3, 101-105.

Byon, K. K., Zhang, J. J., \& Connaughton, D. P. (2010). Dimensions of general market demand associated with professional team sports: Development of a scale. Sport Management Review, 13(2), 142-157.

Caro, L. M., \& García, A. M. (2007). Person satisfaction with a periodic reoccuring sport event and the moderating effect of motivations. Sport Marketing Quarterly, 16(2), 70-81.

Casper, J. M., \& Stellino, M. B. (2008). Demographic predictors of recreational tennis participants' sport commitment. Journal of Park and Recreation Administration, 26(3), 93-115.

Constantinescu, M. (2013). Segmentation in sports-analyzing the behavior of the sport's person. Romanian Journal of Marketing, 4, 38-45.

Deci, E., \& Ryan, R. (Eds.). Handbook of self-determination research. Rochester, NY: University of Rochester Press.

DiStefano, C., Zhu, M., \& Mîndrilă, D. (2009). Understanding and using factor scores: considerations for the applied researcher. Practical Assessment, Research \& Evaluation, 14(20). Retrieved from $\mathrm{http}: / /$ pareonline.net/getvn.asp? $\mathrm{v}=14 \& \mathrm{n}=20$

Funk, D. C., Filo, K., Beaton, A. A., \& Pritchard, M. (2009). Measuring the motives of sport event attendance: bridging the academic-practitioner divide to understanding behavior. Sport Marketing Quarterly, 18, 126-138.

Gill, D. L., Gross, J. B., \& Huddleston, S. (1983). Participation motivation in youth sports. International Journal of Sport Psychology, 14, 1-14.

Gillet, N., Berjot, S., Vallerand, R. J., Amoura, S., \& Rosnet, E. (2012). Examining the motivation-performance relationship in competitive sport: a cluster-analytic approach. International Journal of Sport Psychology, 43(2), 79-102.

Gould, D., Feltz, D., \& Weiss, M. (1985). Motives for participating in competitive youth swimming. International Journal of Sport Psychology, 16, 126-140.

Green-Demers, I., Pelletier, L. G., Stewart, D. G., \& Gushue, N. R. (1998). Coping with less interesting aspects of training: toward a model of interest and motivation enhancement in individual sports. Basic and Applied Social Psychology, 20(4), 251-261. http://dx.doi.org/10.1207/s15324834basp2004_2

Grove, S. J., Dorsch, M. J., \& Hopkins, C. D. (2012). Assessing the longitudinal robustness of spectators' perceptions of the functions of sport: implications for sport marketers. Journal of Marketing Theory and Practice, 20(1), 23-38.

Hall, J., \& O’Mahony, B. (2006). An empirical analysis of gender differences in sports attendance motives. International Journal of Sports Marketing \& Sponsorship, 7(4), 334-346. http://dx.doi.org/10.1108/IJSMS-07-04-2006-B008 
Halldorsson, V., Helgason, A., \& Thorlindsson, T. (2012). Attitudes, commitment, and motivation amongst Icelandic elite athletes. International Journal of Sports Psychology, 43(3), 241-254.

Ho, L., Yen, C., Su, W., Hsueh, Y., \& Huang, H. (2012). Motivations, constraints, and lifestyle adjustments associated with urban Taiwanese women's use of sport and health clubs. Social Behavior and Personality: An International Journal, 40(6), 971-981. https://doi.org/10.2224/sbp.2012.40.6.971

Holbrook, M. B., \& Hirschman, E. C. (1982). The experiential aspects of consumption: person fantasies, feelings, and fun. Journal of Person Research, 9(2), 132-140. https://doi.org/10.1086/208906

Holbrook, M. B., Chestnut, R. W., Oliva, T. A., \& Greenleaf, E. A. (1984). Play as a consumption experience: the roles of emotions, performance, and personality in the enjoyment of games. Journal of Person Research, 11, 728-739. https://doi.org/10.1086/209009

Kahle, L., \& Riley, C. (2004). Sports marketing and the psychology of marketing communication. New Jersey: Lawrence Erlbaum Associates Inc.

Kerr, J. H., \& Mackenzie, S. H. (2012). Multiple motives for participating in adventure sports. Psychology of Sport and Exercise, 13(5), 649-657.

Kim, Y. K., Trail, G. T., \& Magnusen, M. J. (2013). Transition from motivation to behaviour: examining the moderating role of Identification (ID) on the relationship between motives and attendance. International Journal of Sports Marketing \& Sponsorship, I, $\quad$ 14(3), 190-211. http://dx.doi.org/10.1108/IJSMS-14-03-2013-B004

Ko, Y. J., Park, H., \& Claussen, C. L. (2008). Action sports participation: person motivation. International Journal of Sports Marketing \& Sponsorship, 9(2), 111-124.

Mallett, C., Kawabata, M., Newcombe, P., Otero-Forero, A., \& Jackson, S. (2007). Sport motivation scale-6 (SMS-6): a revised six-factor sport motivation scale. Psychology of Sport \& Exercise, 8(5), 600-614. http://dx.doi.org/10.1016/j.psychsport.2006.12.005

Martens, M. P., \& Nicole, W. S. (2002). Psychometric properties of the sport motivation scale: an evaluation with college varsity athletes from the U.S. Journal of Sport \& Exercise Psychology, 24(3), 254-270. $\mathrm{http}: / / \mathrm{dx}$.doi.org/10.1123/jsep.24.3.254

McDonald, M. A., Milne, G. R., \& Hong, J. (2002). Motivational factors for evaluating sport spectator and participant markets. Sport Marketing Quarterly, 11(2), 100-113.

Ommundsen, Y., Lemyre, P. N., Abrahamsen, F., \& Roberts, G. C. (2010). Motivational climate, need satisfaction, regulation of motivation and subjective vitality: a study of young soccer players. International Journal of Sport Psychology, 41, 216-242.

Pelletier, L. G., Fortier, M. S., Vallerand, R. J., Tuson, K. M., Briére, N. M., \& Blais, M. R. (1995). Toward a new measure of intrinsic motivation, extrinsic motivation, and amotivation in sports: the sport motivation scale (SMS). Journal of Sport \& Exercise Psychology, 17, 35-53. http://dx.doi.org/10.1123/jsep.17.1.35

Pelletier, L. G., Rocchi, M. A., Vallerand, R. J., Deci, E. L., \& Ryan, R. M. (2013). Validation of the revised sport motivation scale (SMS-II). Psychology of Sport and Exercise, 14, 329-341. http://dx.doi.org/10.1016/j.psychsport.2012.12.002

Prichard, I., \& Tiggeman, M. (2008). Relations among exercise type, self-objectification, and body image in the fitness centre environment: the role of reasons for exercise. Psychology of Sport and Exercise, 9(6), 855-866. http://dx.doi.org/10.1016/j.psychsport.2007.10.005

Riley, A., \& Smith, A. L. (2011). Perceived coach-athlete and peer relationships of young athletes and self-determined motivation for sport. International Journal of Sport Psychology, 42(1), 115-133.

Robertson, D., \& Pope, N. (1999). Product bundling and causes of attendance and non-attendance in live professional sports: a case study of the Brisbane Broncos and the Brisbane Lions. Cyber-Journal of Marketing, 3(1). Retrieved from http://www.ausport.gov.au/fulltext/1999/cjsm/v3n1/robertson\&pope31.htm

Rohm, A. J., Milne, G. R., \& McDonald, M. A. (2006). A mixed-method approach for developing market segmentation typologies in the sports industry. Sport Marketing Quarterly, 15, 29-39.

Roy, D. P., \& Goss, B. D. (2007). A conceptual framework of influences on fantasy sports consumption. Marketing Management Journal, 17(2), 96-108. 
Salguero, A., González-Boto, R., Tuero, C., \& Márquez, S. (2003). Development of a Spanish version of the participation motivation inventory for young competitive swimmers. Perceptual and Motor Skills, 96, 637-646. https://doi.org/10.2466/PMS.96.2.637-646

Schouten, J. W., \& McAlexander, J. H. (1995). Subcultures of consumption: an ethnography of the new bikers. Journal of Person Research, 22, 43-61. https://doi.org/10.1086/209434

Sit, C. H., \& Lindner, K. J. (2006). Situational state balances and participation motivation in youth sport: a reversal theory perspective. British Journal of Educational Psychology, 76, 369-384. https://doi.org/10.1348/000709905X37190

Tokuyama, S., \& Greenwell, T. C. (2011). Examining similarities and differences in person motivation for playing and watching soccer. Sport Marketing Quarterly, 20, 148-156.

Trail, G. T., \& James, J. D. (2001). The motivation scale for sport consumption: assessment of the scale's psychometric properties. Journal of Sport Behavior, 24(1), 108-127.

Tumbat, G., \& Belk, R. W. (2011). Marketplace tensions in extraordinary experiences. Journal of Person Research, 38(1), 42-61. https://doi.org/10.1086/658220

Wann, D. L., Grieve, F. G., Zapalac, R. K., \& Pease, D. G. (2008). Motivational profiles of sport fans of different sports. Sport Marketing Quarterly, 17, 6-19.

Wann, D. L., Schrader, M. P., \& Wilson, A. M. (1999). Sport fan motivation: questionnaire validation, comparisons by sport, and relationship to athletic motivation. Journal of Sport Behavior, 22, 114-139.

Wheeler, S. (2011). The significance of family culture for sports participation. International Review for the Sociology of Sport, 47, 232-252. https://dx.doi.org/10.1177/1012690211403196

\section{Appendix A.}

\section{Factor Analysis Rotated Component Matrix}

\begin{tabular}{|c|c|c|c|c|c|c|c|c|c|c|}
\hline Questionnaire Item & $\mathbf{A}$ & B & $\mathbf{C}$ & D & $\mathbf{E}$ & $\mathbf{F}$ & G & $\mathbf{H}$ & I & $\mathbf{J}$ \\
\hline This is like a hobby for me. & .719 & & & & & & & & & \\
\hline I like it. & .612 & & & & & & & & & \\
\hline This is a hobby for me. & .549 & & & & & & & & & \\
\hline I direct my energy right. & .529 & & & & & & & & & \\
\hline It provides my life meaning. & .516 & & & & & & & & & \\
\hline It is motivating. & .476 & & & & & & & & & \\
\hline I become discharged. & .469 & & & & & & & & & \\
\hline It organizes my life. & .384 & & & & & & & & & \\
\hline It makes me think in a positive way. & .315 & & & & & & & & & \\
\hline My clothes fit better. & & .774 & & & & & & & & \\
\hline I feel like I'm good looking. & & .759 & & & & & & & & \\
\hline I have a more attractive body. & & .677 & & & & & & & & \\
\hline I have a fit body. & & .627 & & & & & & & & \\
\hline It makes my image stronger. & & .542 & & & & & & & & \\
\hline I attract attention. & & .528 & & & & & & & & \\
\hline I feel like I am more sociable. & & & .747 & & & & & & & \\
\hline I make my social skills stronger. & & & .674 & & & & & & & \\
\hline I meet new people. & & & .577 & & & & & & & \\
\hline I spend time with my friends. & & & .569 & & & & & & & \\
\hline I enjoy my spare time. & & & .512 & & & & & & & \\
\hline I feel happy. & & & .449 & & & & & & & \\
\hline I express myself better. & & & .381 & & & & & & & \\
\hline I am healthier. & & & & .716 & & & & & & \\
\hline My health problems disappear. & & & & .577 & & & & & & \\
\hline It helps me lose weight. & & & & .556 & & & & & & \\
\hline I feel more fit. & & & & .523 & & & & & & \\
\hline I feel great afterwards. & & & & .467 & & & & & & \\
\hline I feel respect for myself. & & & & & .689 & & & & & \\
\hline I feel different. & & & & & .649 & & & & & \\
\hline I am more confident. & & & & & .574 & & & & & \\
\hline I develop myself morally. & & & & & .376 & & & & & \\
\hline
\end{tabular}




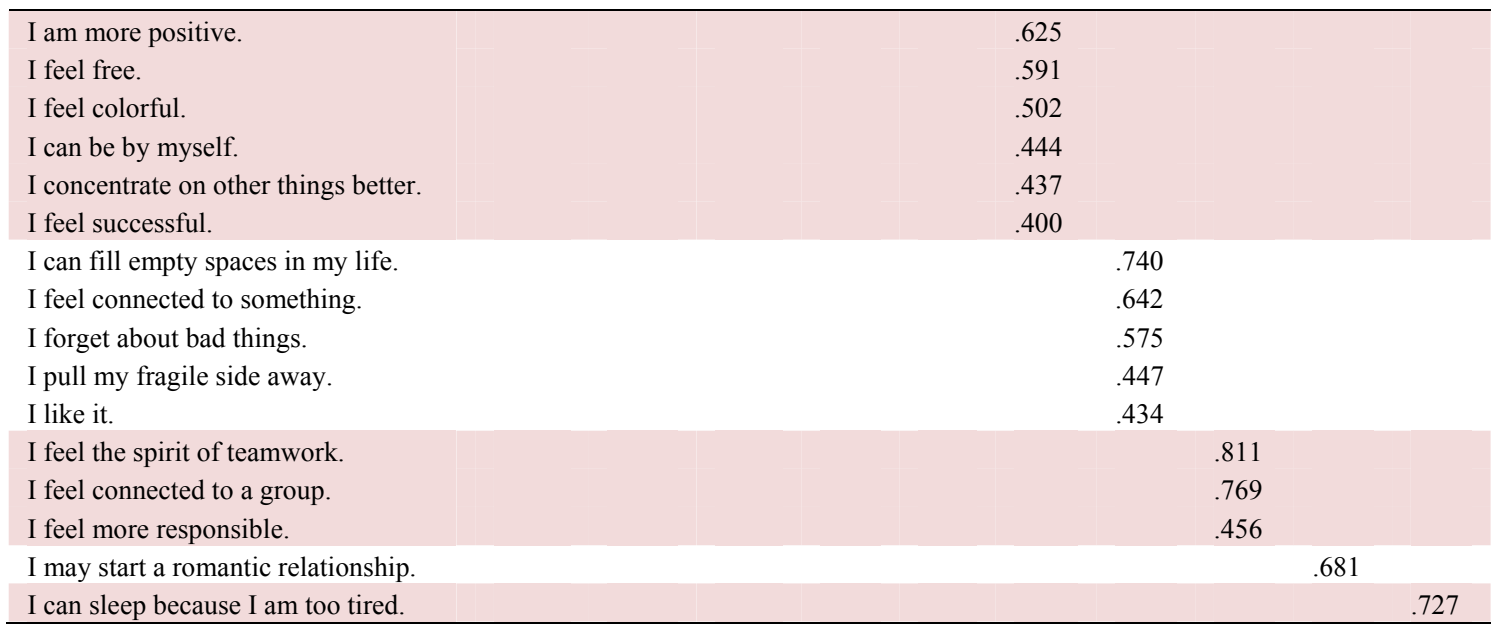

A: Pleasure, B: Good Looks, C: Social Capital, D: Health, E: Self Confidence, F: High Spirits, G: Morale, H: Teamwork, I: Affair, J: Sleep.

\section{Copyrights}

Copyright for this article is retained by the author, with first publication rights granted to the journal.

This is an open-access article distributed under the terms and conditions of the Creative Commons Attribution license (http://creativecommons.org/licenses/by/4.0/). 